\title{
LA VUELTA DEL PADRE Y OTRAS APARICIONES: FANTASMAGORÍAS DE UN PAISAJE EN GEOLOGÍA DE UN PLANETA DESIERTO DE PATRICIO JARA.
}

\author{
THE RETURN OF THE FATHER AND OTHER APPEARANCES: \\ PHANTASMAGORIAS OF A LANDSCAPE IN GEOLOGÍA DE UN PLANETA \\ DESIERTO BY PATRICIO JARA.
}

\author{
Cristofer Cepeda García \\ Universidad de Playa Ancha de Ciencias de la Educación. Chile \\ cristofer.cepeda.garcia@gmail.com
}

\begin{abstract}
Resumen. Geología de un planeta desierto (2013) de Patricio Jara es una novela cuya enunciación arranca con la aparición del fantasma del padre de Rodrigo frente a su departamento. La invitación que el padre hace a su hijo a salir a dar una vuelta, y el consiguiente recorrido que ambos realizan por la ciudad de Antofagasta permitirá la enunciación de un paisaje fantasmagórico como resultado del encuentro que el narrador sostiene con el espacio que habita, espacio cuyos recovecos desprenderán una estela espectral propiciada por el acto de recordar. Serán estos elementos los que darán cuenta de las ruinas y la serie de despojos humanos que el neoliberalismo deja atrás de la mano de la industria minera en los territorios del Norte de Chile, y que operan como trasuntos de la vida del padre, y de su muerte.
\end{abstract}

Palabras clave. Geología de un planeta desierto - paseo - paisaje - fantasmagoría neoliberalismo.

Abstract. Geología de un planeta desierto (2013) by Patricio Jara is a novel that starts with the appearance of the ghost of Rodrigo's father in front of his apartment. The invitation that the father makes to his son to go out for a walk and the consequent journey that both make through the city of Antofagasta will allow the enunciation of a ghostly landscape as a result of the encounter that the narrator maintains with the space he inhabits, a space whose nooks and crannies will give off a spectral trail caused by the act of remembering. These elements will account for the ruins and the series of human remains that neoliberalism leave behind at the hands of the mining industry in the northern territories of Chile, which operate as transcripts of the father's both life, and death.

Keywords. Geología de un planeta desierto - walk - landscape - phantasmagoria capitalism.

Recibido: 29 de septiembre de 2021

Aceptado: 16 de noviembre de 2021 
Artículo. Cristofer Cepeda García. "La vuelta del padre y otras apariciones: Fantasmagorías de un paisaje en Geología de un planeta desierto de Patricio Jara"

\section{Introducción}

Patricio Jara, escritor y periodista nacido en Antofagasta (1974) ha publicado diversos artículos y crónicas en distintos medios del país. Entre sus novelas se cuentan De aquí se ve tu casa (1999), El sangrador (2002), Quemar un pueblo (2009), Antipop (2016), Dios nos odia a todos (2017), El cielo rojo del norte (2018), y Tragar el sol (2020), por nombrar algunas.

El proyecto narrativo de Jara es diverso. Va desde la escritura de crónicas referidas a la escena del Metal, el cruce entre el periodismo histórico y la ficción, y la fijación del Norte Grande como espacio narrativo. En esa línea la apuesta narrativa de Jara pareciera intencionar el cartografiar el norte desde una dimensión temporal e histórica, ya sea remitiéndose a ciertos hitos del pasado histórico que formaron parte de la ocupación del estado de Chile sobre los territorios de Bolivia y Perú, ya sea rastreando los efectos del paso del tiempo y del curso mismo del capitalismo sobre sus ciudades y sus habitantes en el Chile de hoy. Dichos textos, puestos en conjunto, parecieran por momentos proponerse fisurar el mito mismo de la nación.

Esta actividad cartográfica que cruza su proyecto escritural dialoga con obras de otros escritores que se han propuesto narrar el norte. El más canónico de todos es Andrés Sabella, quien mediante su novela Norte Grande (1944) se propuso novelar la historia de la explotación del salitre, y la de sus trabajadores y familias. Un texto cargado de épica popular que va desde los hallazgos de los yacimientos que conformaron la escena económica local hasta las más grandes masacres de trabajadoras y trabajadores que ha visto la historia de Chile por parte del estado y de su propio ejército. El esfuerzo de Sabella, probablemente el más reconocido, fue antecedido por otras novelas como Carnalavaca (1932) del escritor y arquitecto Andrés Garafulic Yancovic, obra que situándose en las inmediaciones de Chuquicamata da cuenta de los perniciosos efectos de la explotación norteamericana en el territorio en complicidad con el estado chileno. De ahí en más se suman otros libros como Hijo del salitre (1952) de Volodia Teitelboim, la narrativa de Salvador Reyes, la de Mario Bahamonde, o la cuentística de Nicolás Ferraro, tradición de la que se hace parte incluso 
Hernán Rivera Letelier, quien a contar de los años noventa comienza a publicar una seguidilla de obras situadas en la pampa, con especial énfasis en los derroteros, saberes y experiencias de los sujetos populares pampeanos.

Geología de un Planeta Desierto (2013) es una novela escrita en primera persona cuya narración arranca con la aparición de un padre muerto: "las cosas ocurrieron más o menos de este modo: un día, luego de diez años muerto, mi papá decidió volver" (9). Su aparición, lejos de suceder dentro de una niebla o como producto de algún mágico artilugio, ocurre una mañana de sábado como cualquier otra en el que éste se presenta frente al departamento de su hijo "llamando a la puerta con tres golpes secos y decididos" (9).

La novela transcurre en gran medida en la ciudad de Antofagasta, siendo ésta junto a la relación paterno-filial entre Rodrigo (el narrador) y su padre sus ejes articuladores. A contar de la aparición del padre muerto, Jara articula un relato donde emerge la narración de episodios diversos vinculados al derrotero de la familia del narrador, familia crecientemente erosionada y tensionada por los efectos de la explotación del régimen de trabajo y del curso mismo del neoliberalismo (privatización, flexibilización laboral, subcontratación), en cuyo caso sus efectos se inscribieron en el cuerpo y en la subjetividad del padre hasta matarlo.

Geología de un planeta desierto es una novela de la que se ha escrito poco. Si bien fue merecedora del premio municipal de literatura de Santiago el año 2014, su escasa recepción por parte de la crítica académica pareciera obedecer al centralismo con la que esta opera, y que relega la lectura de obras de provincias y fronteras a la marginalidad y al silencio. Dicho esto, son dos los textos críticos que alimentan el estado del arte: "Geología de un planeta sombrío" (2018) de Felipe Arancibia Venegas y "Orfandades de la globalización en la novela Geología de un planeta desierto de Patricio Jara” (2019) de Sergio Pizarro Roberts.

Felipe Arancibia Venegas en el artículo citado explora la relación problemática que sostienen padre e hijo en el marco de la novela. Para Arancibia, la figura del fantasma del padre operaría como una metonimia de la ciudad y del desierto que les rodea en la medida que ambos se han visto afectados por el auge de la explotación minera. De este modo, la aparición del fantasma del padre desde un punto de vista psicoanalítico funcionaría como la exteriorización de un deseo; de hacer vivir al padre por medio de la ficción. Dicha operación permitiría explorar una serie de recuerdos donde poco a poco se iría liberando un rencor reprimido: hacia las empresas mineras, hacia las políticas neoliberales y hacia el capitalismo 
Artículo. Cristofer Cepeda García. "La vuelta del padre y otras apariciones: Fantasmagorías de un paisaje en Geología de un planeta desierto de Patricio Jara"

en general, en tanto culpables estructurales de un mal que modificó la fisionomía completa de la ciudad y sus habitantes. De allí que Arancibia identifique en la novela un develamiento de la ideología capitalista de explotación y consumo.

Sergio Pizarro Roberts, por otra parte, articula una lectura donde la relación conflictiva entre padre e hijo es central. Para Pizarro dicha relación está tensada por la pulsión de muerte bajo la figura freudiana de matar al padre. La doble muerte del padre, producto de la enfermedad primero, y de su desvanecimiento en el aire después, arrojaría al narrador a una doble orfandad exacerbada por la globalización. Este fenómeno histórico, de carácter mundial, tendería a desterritorializar los circuitos de producción y consumo dibujando nuevas cartografías globales. Si consideramos siguiendo a Pizarro que parte de la trayectoria vital del protagonista se desarrolla por razones de trabajo y después de la muerte del padre, en distintos rincones del continente, el efecto de orfandad se vería reforzado en el horizonte de la globalización. De ahí en más su propuesta de lectura procede rastreando los ecos de la globalización como productos de consumo cultural que irán delineando la subjetividad del narrador durante sus años de formación para luego generar un quiebre motivado por el develamiento de la crisis económica y de sentido que la propia globalización va suscitando en los distintos territorios y en las vidas de sus habitantes.

Interesa para el caso del presente artículo retomar el problema de la relación paterno filial planteada por ambos autores. Su novedad estará en pensar por medio de otros recursos teóricos un procedimiento literario que articula al conjunto de la novela. Me refiero al paseo como actividad que moviliza la narración, y que al poner en relación al sujeto con el territorio construye una determinada forma de paisaje. Será la invitación del fantasma del padre a salir "a dar una vuelta" (Jara, 32) lo que permitirá la enunciación de un paisaje espectral como resultado de la emergencia de cuerpos dolientes, cuerpos desechados por el neoliberalismo y la explotación minera que aparecen en el espacio mediante el acto de recordar.

Como parte de la metodología de análisis importará soportar teóricamente una cierta noción de fantasma en diálogo con la posibilidad del paisaje fantasmagórico. El punto de clivaje entre ambos conceptos vendrá dado por la categoría de sujeto, clivaje que permitirá situar la aparición del fantasma del padre como resultado de un determinado proceso de subjetivación del hijo enmarcado en la conflictiva relación paterno-filial, para luego exteriorizarla en la emergencia de un paisaje poblado de fantasmas. Será en este punto en 
que el paisaje que emerge como resultado del encuentro del narrador con el espacio irá reconfigurándose a partir nuevos elementos perfilados por su trabajo como geólogo y que permitirán, mediante la enunciación de una experiencia estética del desierto, la superación del conflicto que sostiene el narrador con su padre, dando así cierre a la novela.

\section{La aparición del fantasma del padre.}

La importancia de la aparición del fantasma del padre muerto consiste en que opera como un dispositivo que motiva la narración. Es a propósito de su presentación frente a la puerta del departamento que Rodrigo relata diversos episodios del pasado vinculados a su figura, a su trabajo en el puerto, y a la serie de condiciones que lo deterioraron progresivamente hasta matarlo.

Otra novela situada en el norte que hace uso del recurso de la vuelta del padre es $E l$ empampado Riquelme (2012) del escritor y también periodista Francisco Mouat. La historia arranca con un narrador que, tras haberse encontrado con la noticia del hallazgo de las osamentas de Julio Riquelme en pleno desierto cuarenta y tres años después de su desaparición, decide emprender una investigación que le permita por un lado imaginar las circunstancias que lo llevaron a morir empampado en pleno desierto, que no es otra cosa que morir seco, asado, disecado por el sol. Y por otro, dimensionar el impacto que dicha aparición significó para su hijo, y para el resto de los integrantes de la familia de Riquelme que aún seguían vivos. En ese sentido, la aparición de ambos, uno en forma de osamenta, el otro en forma de fantasma, plantearía la exigencia de un deseo que se satisface en la medida que sucede el propio acto de narrar.

Para Didi-Huberman dicha exigencia emergería de la deuda contraída por el testigo con aquellas imágenes que observa, referidas a hechos de violencia extrema que se resisten a ser pensadas: "debemos contemplarlas, asumirlas, tratar de contarlas" (18). Tal deuda ocurriría por la propia aparente imposibilidad de pensar cierto tipo de violencia que desborda nuestra imaginación, cuestión que los narradores de ambas novelas refieren, y frente a lo cual consignarían su deseo de movilizar aquellos hechos del terreno de lo indecible a lo decible:

No olvido la tarde de sábado en que leí en el diario la noticia del hallazgo de Julio Riquelme Ramírez en el desierto, con todos sus huesos y tendido 
Artículo. Cristofer Cepeda García. "La vuelta del padre y otras apariciones: Fantasmagorías de un paisaje en Geología de un planeta desierto de Patricio Jara"

al sol (...) El recorte y sobre todo lo que no decía esa breve nota, los misterios y las preguntas que uno podía hacerse después de leer las primeras informaciones, convirtieron desde esa misma tarde todo lo relativo a Riquelme en una obsesión. (Mouat, 9)

De eso, tarde o temprano, vamos a contar algunas cosas: de qué carajos puedes hacer cuando alguien que no está, que no puede estar, que no debe volver, de pronto vuelve un sábado después de almuerzo. A ver si la respuesta está en otra parte que no sea la biología. (Jara, 15)

Ambas novelas, la de Jara y la de Mouat hacen de la aparición de la imagen un vestigio del paso del tiempo: cuarenta y tres años para quienes atestiguaron la vuelta de Riquelme, diez en el caso Rodrigo y Magaly. Para Benjamin la ruina en relación al tiempo constituye el sustrato material de la experiencia misma que los sujetos tienen de ella en el horizonte de la modernidad. Dicha experiencia estaría enmascarada por la noción de progreso, suerte de fetichización del futuro que empujaría la mirada hacia adelante, al tiempo que detrás, hacia el pasado, el progreso arroja "ruinas sobre ruinas, amontonándolas sin cesar" (11). La aparición de dichas ruinas construiría en ambas novelas la idea del desierto como un monstruo atemporal y primigenio, un coloso que como el océano devuelve los vestigios de antiguas catástrofes a través de su oleaje. De allí que pensar la aparición del padre como una ruina del paso del tiempo, implique a su vez pensar la relación entre el tiempo y el espacio, y la serie de variables culturales que intervienen ambas coordenadas, en cuyo caso el capitalismo ocupa un papel central.

La aparición del fantasma del padre en la novela de Jara constituye la imagen de un hecho límite: "la persona que estaba en el living del departamento efectivamente había vuelto luego de una década dentro de un nicho de un cementero municipal y no era un zombie ni un vampiro ni un monstruo ni nada parecido" (Jara, 13). El impacto que dicha aparición provoca es el resultado de lo que pareciera ser la ausencia de ciertas marcas que en la figura del padre acusen el paso del tiempo:

Era él: sus ojos pardos, su nariz de puente recto y puntiagudo y su sonrisa que, lejos de ser contagiosa, siempre transmitía una seguridad inquebrantable. Parecía el mismo de los días previos a la enfermedad. Incluso diría que un poco más rejuvenecido, y así, parado frente a la puerta, de pronto tuve la sensación de que el enfermo era yo. (9) 
La diferencia entre la aparición del fantasma del padre en la novela de Jara y las osamentas de Riquelme en la novela de Mouat estribaría en ese punto; mientras la primera pareciera funcionar como una imagen que se sustrae al tiempo, la segunda acusa el propio paso del tiempo en su materialidad. Dicha diferencia guarda relación con el aparejamiento que pareciera existir entre la figura del fantasma y la fotografía, en cuyo caso, el efecto que ambas provocan en el espectador consistiría en inducir la formulación de la pregunta en suspenso por el cuerpo ausente, y sobre el cual el paso del tiempo sí se inscribe.

La descripción que hace el narrador sobre su padre repara en el aspecto visual al tiempo que recalca la inmutabilidad de su fisionomía como si se tratase del hallazgo de una fotografía olvidada en algún cajón. El efecto espectral de lo observado induciría esa suerte de extrañamiento frente al hallazgo que llevaría incluso a Magaly afirmar: "Rodrigo, esta persona es tu papá” (Jara, 11).

El dispositivo montado por la novela a propósito de su aparición da cuenta de una cámara oscura en cuyo caso la puerta hace las veces de umbral, y el telón de fondo ese cielo “cubierto por un borbotón de nubes perfectamente blancas desplazándose sobre la bahía de Antofagasta" (9). La materialidad de la imagen del padre que asalta sobre ese telón viene dada por la serie de constataciones que realiza Magaly, y que develan al sujeto como espectralidad, como una fotografía o negativo de un original:

Al cabo de unos minutos, le había comprobado el pulso, la temperatura, la frecuencia cardiaca, la presión arterial y otros signos vitales de segundo orden, como su reacción al dolor (le apretó un dedo) y el tamaño de sus pupilas (le abrió los párpados todo lo que pudo) (...) En ninguno había el menor rastro de vida. (12)

La idea de la casa como cámara oscura dialoga con lo observado por Didi-Huberman a propósito de la serie de fotografías tomadas por sobrevivientes judíos al interior de los campos de exterminio, donde la propia oscuridad del ocultamiento permitiría enfocar, hacer la operación de recorte de realidad. La cámara oscura, instrumento con forma de caja que permite el ingreso de una mínima cantidad de luz para proyectar una imagen del exterior en una de sus paredes, fue usada luego como base para la producción de fotografías. Dentro del dispositivo montado por la novela, la cámara oscura permitiría develar el sustrato material de la vuelta del padre como una imagen en negativo: 
Artículo. Cristofer Cepeda García. "La vuelta del padre y otras apariciones: Fantasmagorías de un paisaje en Geología de un planeta desierto de Patricio Jara"

Fue una mirada fugaz, un momento de atención a un detalle minúsculo: mientras estaba en el balcón, noté que el viejo tenía los pies unos centímetros levantados del suelo. De inmediato pensé que era algún efecto visual por la falta de luz, pues entonces había atardecido y el departamento comenzaba a quedarse a oscuras como una bóveda, pero la imagen de mi papá suspendido en el aire, acaso levitando, se me hizo nítida y me vino acompañada por una opresión en el pecho, de esas tan fuertes que sabes que si no haces algo rápido puedes caer rendido. Entonces encendí la lámpara del comedor y junto con las sombras desapareció lo que entonces creí ver. (Jara, 32)

El detalle que impacta al narrador y a partir del cual compone la escena es la suspensión del padre en el aire a propósito de la escasa luz nadiral que ingresa por el balcón hacia el departamento. Cuando observamos la luz, o notamos la materialidad de la luz como un halo que ingresa desde alguna parte, lo que vemos son pequeñas partículas de polvo en suspensión. Para Didi-Huberman el polvo nos mostraría de este modo "que existe un vínculo profundo de la luz con la suspensión" (59), siendo lo que está suspendido "la sustancia misma de esa luz". La operación metonímica establecería una continuidad espacial entre el polvo iluminado por la luz, y la luz misma, fundiéndolos en una misma cosa.

La importancia de la "bóveda" o cámara oscura al momento de enfrentarnos a la imagen del padre radica en revelar su presencia frente al narrador como el resultado de una inversión. Sarah Kofman en La cámara oscura de la ideología (1975) bajo el propósito de expandir la noción de cámara oscura como metáfora del efecto de la ideología sobre los sujetos acuñada por Karl Marx en La ideología alemana (1932), señala que desde las teorías científicas acerca del funcionamiento del ojo en relación a la luz, el modelo explicativo de la cámara oscura implicaría "la existencia de un dato que se presenta siempre ya invertido" (20). La inversión que opera en la escena de la novela, consistiría de este modo en hacer parecer que la imagen del padre "no fuese una excitación subjetiva del nervio de la vista, sino la forma material de un objeto situado fuera del ojo" (26), de modo similar a cómo funciona la fetichización de las mercancías donde éstas aparecen como objetos autónomos no ligados al trabajo que las produce. Que el padre levite al igual que el polvo iluminado por la luz referido por Didi-Huberman es el centro del detalle que inquieta al narrador, y que indicaría una suerte de línea demarcatoria entre padre e hijo en cuyo caso la sustancia lumínica del padre formaría 
parte del territorio de la espectralidad de las imágenes. La urgencia del narrador por apagar la cámara oscura, encender la luz y velar con ello la imagen, vendría dada por la amenaza de la insalvable distancia que esa misma demarcación implica.

La cuestión espectral suscitada por la imagen no es solo resultado de la inscripción en su soporte material de un cuerpo ausente al que esa imagen refiere, sino también por aquella ausencia que el sujeto que observa acusa en esa imagen. En ese sentido, la estela fantasmagórica que emerge de ese encuentro estará determinada en gran medida por aquellas cuestiones que el sujeto sea capaz de recordar sobre el cuerpo referido en la imagen, y que la desdibujan, escenificando una suerte de diplopía, desenfoque, o imagen afantasmada.

Desde una dimensión psicoanalítica, la emergencia de la imagen del fantasma del padre se originaría en la propia subjetividad del narrador, exteriorizándose a propósito de un hecho traumático que "vela y enmarca lo real entendido como lo irrepresentable" (Díaz, 52). Este ángulo de lectura con respecto a la imagen del fantasma haría transitar su aparición hacia una emergencia como resultado de un conflicto subjetivo. Dicha emergencia, en ese sentido, aparejaría en un plano de encuentro la imagen de su aparición, con el padre que emerge y acecha como resultado de la inscripción de un trauma, y que el narrador refiere como un suceso previo a su aparición en los siguientes términos:

Admito que al principio la situación que voy a contar me tuvo por las cuerdas; pensaba que me estaba volviendo loco, que me estaba comenzando a rayar, pues empecé a ver a mi papá en cada nuevo lugar donde iba. En los años que estuve fuera de Chile lo vi en un redondel a la entrada de Ciudad Merliot, en San Salvador, y dos días después tomando un desayuno de tres dólares en el Wendy’s de avenida de la Revolución; lo vi bajándose entre un ejército de turistas de un vagón del tren interno que recorre el aeropuerto DFW en Texas; lo vi afuera de un restaurante en la British Columbia en Canadá. (Jara, 29)

El contenido de ese trauma, y que haría emerger la cuestión espectral tras el encuentro entre el observador y la imagen, surge a partir del proceso de erosión que condujo al padre del narrador a su muerte, y del cual el este fue testigo: "El viejo quedó con un evidente daño neuronal. Fue como si de pronto volviera de ser niño. Al perder parte de su motricidad, desde entonces hubo que bañarlo, darle la comida en la boca, afeitarlo, sacarle los mocos de la nariz" (83). La inscripción del trauma, en ese sentido, implicaría la existencia de una operación de escamoteo en el curso de la experiencia del sujeto que haría permanecer al duelo 
Artículo. Cristofer Cepeda García. "La vuelta del padre y otras apariciones: Fantasmagorías de un paisaje en Geología de un planeta desierto de Patricio Jara"

en suspenso. Dicho efecto sería el resultado de la ausencia de ciertos recursos simbólicos que permitan leer la urdimbre detrás de la muerte del padre en su real complejidad.

El trasunto de ese escamoteo radica en el señalamiento del padre como un sujeto enfermo y/o responsable de su propia muerte, señalamiento que horada la propia trama familiar, y que oculta bajo la medicalización del síntoma, cómo el capital explota y desecha los cuerpos bajo una lógica de producción predatoria. En consecuencia, la tachadura que pesa sobre la subjetividad del padre es traspasada a su vez sobre su hijo bajo la forma de una tensión que lo hace sujeto de responsabilidad acerca del destino del primero: "podría hacerme muchas preguntas, preguntas médicas y otras desde el sentido común, especialmente porque uno siempre tiene la idea de que se pudo hacer algo más" (92), y sujeto cómplice de ese señalamiento que bajo la lógica del capital invierte el orden de las cosas, confundiendo víctima con victimario. De allí que el contenido de la fantasmagoría, su forma, que el narrador enuncia a propósito de la imagen de la visita del padre, esté en gran medida determinada por el ejercicio de repensar su muerte como efecto de la inscripción de un trauma a propósito de una violencia límite, y de la que esta imagen sirve de archivo.

\section{El paseo junto al fantasma del padre.}

El relato que articula el narrador de la novela de Jara emerge como resultado del paseo que este realiza junto a Magaly, y al fantasma de su padre, paseo que permitirá mediante el ejercicio de recordar la construcción de una suerte de semblanza donde la imagen armada de retazos del padre en vida se superpone a la imagen del padre que les acompaña, haciendo emerger la fantasmagoría.

El recorrido que estos realizan lo acerca a novelas como Canción de navidad de Charles Dickens en donde su protagonista, el avaro Scrooge, es visitado en su casa por los fantasmas de las navidades pasadas, presentes y futuras, quienes lo llevan a dar un paseo por la ciudad para así atestiguar las consecuencias de su usurero actuar. En ese sentido la novela de Jara moviliza a través de la invitación del fantasma del padre a salir de casa la figura del paseo como eje articulador de la trama: 
"Bueno, vamos a dar una vuelta", insistió.

"No, papá".

"Qué no. Vamos, vamos, vamos".

"¿Y si nos encontramos con alguien? ¿Se imagina?"

No vamos a ver a nadie, no vamos a hablar con nadie. Quién se va a acordar de mí".

Finalmente hicimos lo que pedía, aunque antes fui a mi ropero y saqué un polerón azul con capucha.

"Póngase esto. Si no, no vamos".

El viejo aceptó y minutos después estábamos los tres caminando por la costanera. (Jara, 33)

El ejercicio de caminar ha formado parte de un importante núcleo articulador de escritura en la historia de la literatura de occidente. Desde la Odisea de Homero en adelante, la escritura de viajes ha permitido la enunciación del paisaje al tiempo que se le recorre. Sin embargo, es quizá desde la Divina Comedia de Dante que el recorrido a pie ha servido como motivo para abarcar un espacio con objeto de describirlo. Durante los siglos XVIII y XIX los textos paisajísticos proliferaron a partir de la marcha de sus autores. Poetas, filósofos y artistas como Rimbaud, Baudelaire, Nietzsche, Benjamin, Thoreau, Rousseau, Cézanne, por nombrar algunos, hicieron del caminar una actividad epistémica y también estética. Aquello permitió ir más allá de una noción monolítica del paisaje para ligarla estrechamente al sujeto y a la cultura desde donde la experiencia paisajística emerge. De allí que para Javier Maderuelo el paisaje se trate "de un constructo, de una elaboración mental que los humanos realizamos a través del fenómeno de la cultura" (12), paisaje que en palabras de Joan Nogué podría pensarse como "un dinámico código de símbolos que nos habla de la cultura" (11). Será el cruce de las categorías de sujeto y espacio mediante el ejercicio del caminar lo que le permitirá a Rebecca Solnit afirmar que:

El ritmo del caminar genera un tipo de ritmo del pensar y el paso a través de un paisaje resuena o estimula el paso a través de una serie de pensamientos. Ello crea una curiosa consonancia entre el pasaje interno y el externo, sugiriendo que la mente es también una especie de paisaje y que caminar es un modo de atravesarlo. (20)

El circuito recorrido por Rodrigo, Magaly, y el fantasma del padre de Rodrigo, comprende distintas locaciones de la ciudad de Antofagasta: Avenida Grecia, el Puerto, Avenida Argentina, calle Homero Ávila, el Parque Japonés, locaciones a partir de las cuales 
Artículo. Cristofer Cepeda García. "La vuelta del padre y otras apariciones: Fantasmagorías de un paisaje en

la descripción del espacio se entrecruza con la serie de recuerdos sobre el padre que el narrador enuncia. Es a través del cruce de la descripción del espacio y del propio acto de recordar que el narrador da cuenta de la emergencia de un paisaje poblado de fantasmas.

Lo fantasmagórico que movilizamos aquí para la adjetivación del concepto de paisaje ha tenido un tratamiento importante desde Marx en adelante para pensar, desde una metáfora óptica, la inversión que efectúa la ideología capitalista en las consciencias de los sujetos de modo tal que las mercancías sean objetos de fetiche por sobre las manos que las producen. El concepto de fantasmagoría usado por Marx en El capital "surge en torno a 1800 y proviene del ámbito de los espectáculos de óptica, más en concreto de las innovadoras sesiones de linterna mágica celebradas en París pocos años después de la Revolución" (Díaz, 53). El contexto desde el cual emerge su uso como herramienta para la crítica es el de la emergencia y la proliferación de la reproducción técnica de la imagen, en cuyo caso sus efectos de inscripción, amplificación o deformación provocarían a su vez notables efectos en la percepción de quien observa, contexto que dicho sea de paso también hablaría de una cultura de la imagen, que recala en la dimensión óptica de los sujetos, donde el individuo que habita las nuevas ciudades del siglo XIX se vuelve un sujeto observador frente a la multitud y a la ciudad misma.

La utilización del concepto de fantasmagoría que aquí interesa no es el de una sociedad de mercancías fetichizadas, de sujetos que no ven, que siendo parte de esa fetichización no dan cuenta de la niebla que les rodea, sino el de la fantasmagoría en tanto fenómeno que resulta de la mirada crítica de quien observa, de quien da cuenta de las cosas como si estuvieran desdibujadas, fuera de su sitio, develando dos cuestiones sobre una misma cosa: la cosa y la trayectoria fantasmática que la produce.

La reconstrucción de esa trayectoria implica un ejercicio de memoria, donde lo que está en disputa es la enunciación de la serie de violencias inscritas en los objetos como efecto del régimen de explotación del capital, en cuyo caso el cuerpo del sujeto es depredado y el objeto salpicado de sangre. La ciudad misma, en ese sentido, configuraría la escenificación de esas violencias silenciadas bajo el proyecto de la modernidad y su teleología del progreso que Benjamin ilustrara en su comentario al Angelus Novus (1920) de Paul Klee, política de la mirada que haría mirar hacia adelante, hacia el futuro por sobre las ruinas que la modernidad deja a su paso. De allí que para Lucía Guerra en el contexto de pensar la ciudad 
en relación a la memoria, el ejercicio del paseo permita un ejercicio escópico de disputa de cierto régimen de verdad que haría de la ciudad, sus calles y sus ruinas, materiales para el montaje de una memoria disidente:

En el caso individual del sujeto que transita sus calles, la materialidad de la ciudad -como espacio de experiencias- hace del entorno urbano, una vertiente de memoria en ese otro flujo de la subjetividad que le adscribe significados muy distintos a los asignados por la memoria oficial. (137)

En la novela, la enunciación del paisaje como fantasmagoría devela la emergencia de cuerpos dolientes en el espacio que se habita, como el de su padre, desechado por el neoliberalismo y la industria minera, y silenciado por el enmascaramiento del relato hegemónico del progreso y de la bonanza del cobre:

Toda esa generación de trabajadores que entró al puerto antes de los 20 años, a los 40 estaba de brazos cruzados pero con dinero en el bolsillo. Ahora que los puertos se iban a privatizar, les dijeron, podrían seguir trabajando como externos, integrarse sin problema en las muchas compañías que prestaban los mismos servicios. Aquello efectivamente fue una opción y como tal duró bastantes años, pero sé que mi papa, aunque nunca lo dijo, a veces no soportaba la humillación de que le pagaran por turno trabajado con billetes y monedas dentro de un sobre café. Tenía que juntar 6 o 7 para tener una cantidad decente. (Jara, 36)

Para el narrador la enunciación del paisaje como fantasmagoría devendría del acto de recordar, de detenerse en determinados sitios de una ciudad higienizada para hacer emerger su espectralidad. Así como en Canción de Navidad la narración ocurre a partir de la escenificación de ciertas situaciones asociadas a lugares, en Geología de un planeta desierto la casa y el trabajo (el departamento familiar y el puerto) configuran las estaciones de un circuito urbano recorrido diariamente por el padre donde las botillerías de Avenida Argentina hacían las veces de lugares de consumo donde distraer el tránsito y la mirada:

Fueron cerca de cuarenta minutos. A cada tanto trataba de buscar la mirada del viejo entre los bordes del capuchón y veía que llevaba los ojos muy abiertos, atento a cada sitio por donde pasábamos. En el trayecto se detuvo dos o tres veces, y todas frente a botillerías con carteles luminosos. No puedo asegurar que haya reconocido los sitios exactamente, pero sí las marcas que se anunciaban. (68) 
Artículo. Cristofer Cepeda García. "La vuelta del padre y otras apariciones: Fantasmagorías de un paisaje en Geología de un planeta desierto de Patricio Jara"

Será la reconstrucción de ese circuito urbano, cotidiano para el padre en vida, lo que permita a su vez la reconstrucción de la escena de un crimen enmascarado bajo la medicalización del malestar como síntoma del uso predatorio del cuerpo.

La primera locación que visitan Magaly, Rodrigo, y el fantasma del padre de Rodrigo después de abandonar el departamento es el puerto: "Llegamos al puerto, el sitio donde mi papá trabajó toda su vida. Él se quedó un momento allí, frente al control de ingreso. Tenía las manos dentro de los bolsillos del polerón y no hacía más que mirar hacia delante, buscando las grúas que ya no estaban" (33-34). El cruce propiciado por el espacio físico del puerto que los tres visitan, y el otro puerto que emerge de las memorias del narrador puebla la escena de fantasmas. El símbolo de esa fantasmagoría es la grúa que el padre busca y no encuentra, estación de trabajo a la que dedicó gran parte de su vida. El destino de esas grúas, tal y como señala Rodrigo, fue terminar como decorado patrimonial en distintos lugares de la avenida costera de la ciudad:

Cuando terminó su vida útil, la municipalidad creó un plan de rescate patrimonial y decidió comprarlas. La idea era instalarlas en el norte, centro y sur del borde costero de la ciudad (...) Hoy son tres grúas que por las noches se iluminan y dejan de parecer lo que son: se transforman en esculturas de colores, casi en objetos de vanguardia. (34)

El eje de la inversión de los valores producto de la fetichización de la que hablara Marx da cuenta de soslayo del trágico sino de sus operarios: mientras las máquinas son museificadas en calidad de monumento, los segundos son relegados al olvido de la jubilación temprana y del alcoholismo. El traslado de las grúas referidas por el narrador, en ese sentido, se inserta dentro de un proceso de privatización del puerto, el cual, sobre la base de la concesión, pasa a manos de privados impactando la morfología misma del lugar y la vida de los sujetos que lo habitan: "Hoy sería capaz de describir exactamente cómo era el puerto de Antofagasta antes de que lo privatizaran y la mitad de su terreno fuese destinado a un centro comercial" (36). Este proceso, del que da cuenta el narrador, se inserta dentro del cambio general suscitado por el neoliberalismo en un sinnúmero de ciudades como síntoma de la modificación de la morfología de los paisajes citadinos. Modificaciones que para Emilio Pradilla se vendrían materializando hace más de tres décadas en las ciudades 
latinoamericanas, las cuales han sido producidas a propósito "de las reformas estructurales que han materializado el cambio de patrón de acumulación de capital en la región, del intervencionismo estatal al neoliberal" (40).

La novela de este modo reúne en el proceso rememorativo del narrador ciertas piezas de memoria que dan cuenta del destino de gran parte de las comunidades del norte, destino cuyo contexto guarda relación con el fin de los Estados de bienestar y que en el caso chileno implicó desde 1975, y sobre a partir de la entrada en vigencia de la Constitución dictatorial de 1980 un creciente proceso de privatización y neoliberalización del Estado. Dicho proceso se enmarca históricamente en lo que David Harvey reconoce como un fenómeno a escala global que proliferó a fines de la década del setenta y que significó “un punto de inflexión revolucionario en la historia económica y social del mundo" (5). El neoliberalismo, de este modo, consistiría en un cuerpo teórico económico doctrinario que sobre la base de un reimpulso de los valores del liberalismo clásico “irrumpe buscando imponer una concepción de la sociedad y del individuo donde la competencia deviene la forma básica de las relaciones sociales, el sello distintivo de la condición humana" (Encina, 11). En consecuencia, para el neoliberalismo "la mejor manera de promover el bienestar del ser humano consiste en no restringir el libre desarrollo de las capacidades y de las libertades empresariales del individuo" (Harvey, 6), debiendo el Estado limitarse a generar un marco jurídicoinstitucional que garantice "derechos de propiedad privada fuertes, mercados libres y libertad de comercio" (6).

Algunos de los efectos de este giro, y de los que la novela da cuenta, implicaron en la práctica la tercerización de algunas ramas de la producción, y el desmantelamiento de gran parte de las empresas estatales, hecho que trajo consigo "la reubicación de los grupos medios asalariados en el sector privado" (Encina, 308), provocando cambios dramáticos en los sujetos tras la trágica pérdida de las condiciones de "la vieja estabilidad del sector público" (308), cuestión que abrió paso a la barbarie de la flexibilización laboral y a la creciente sensación de incertidumbre. Aquello que resulta de esos cuerpos puestos a la deriva son las trazas de una historia de las que el recorrido entre padre e hijo permite dar cuenta.

La segunda locación que visitan los tres es el departamento familiar, el lugar donde el narrador vio a su padre en un constante ir y venir que difuminaba las fronteras entre el puerto y la casa, el trabajo y el descanso, haciéndolo parte de un mismo circuito intensivo de 
Artículo. Cristofer Cepeda García. "La vuelta del padre y otras apariciones: Fantasmagorías de un paisaje en Geología de un planeta desierto de Patricio Jara"

explotación: “Aquel fue el último lugar que mi papá decidió visitar esa noche: el edificio de nuestro departamento vacío, el balcón común desde donde se asomaba a esperar los barcos que iban rumbo al puerto" (107). Los recuerdos articulados por ese nudo espacio-narrativo dan cuenta de una disposición permanente al trabajo que gobierna la mirada. Dicha política da cuenta del trabajo, la casa, y el espacio de tránsito que media entre ambos como un continuo que superpone las lógicas de la fábrica a la ciudad misma; "El mando sobre la ciudad se estructura como mando sobre la vida: el tiempo y el espacio se ordenan para la producción y el consumo" (Negri, 85). Ese modo de habitar el espacio por parte de los sujetos no solo impediría el descanso, sino la realización de cualquier marco identitario más amplio que el de un sujeto trabajador. La jubilación temprana del padre, en ese sentido, es el punto de quiebre donde el sujeto es desechado y su identidad se rompe. De ahí en más los recuerdos relatados a propósito del departamento describen su creciente proceso de erosión, su conducta errática, sus idas y venidas por las botillerías de Antofagasta, las borracheras, el choque automovilístico, la cirrosis hepática, la hospitalización y la muerte. De allí que el destino del padre sea la expresión del curso mismo del neoliberalismo y su régimen de explotación intensivo que usa recursos y luego los desecha tapándolos con centenares de camionadas de tierra, como Chuquicamata, la ciudad minera enterrada:

La minería es un animal que se alimenta de su propia cola. En el próximo siglo, más que vestigios, más que ruinas para ser estudiadas, los investigadores que exploren Chuquicamata encontrarán un enorme basurero y, debajo, poblaciones completas, hospitales, escuelas, plazas y multicanchas de cemento. (Jara, 96)

El trasunto de esa construcción paisajística es la relación entre el sujeto y el olvido como efecto del capitalismo y del paso del tiempo, cruce desde el cual la memoria haría el trabajo de reconstrucción, de dispositivo que haría emerger en el espacio, a partir de ciertos materiales urbanos, los fantasmas de aquello que ya no está. El destino del padre, y el de la propia ciudad de Chuquicamata en tanto cuerpos desechados por el capitalismo se transforman de esta manera en el anuncio del fin donde la propia ciudad de Antofagasta será enterrada y olvidada cuando el cobre y el litio se acaben en tanto zona de sacrificio bajo las arenas del tiempo: "el desierto, a fin de cuentas, poco a poco se iba metiendo en el barrio sin que nadie entonces se diera cuenta" (104), siendo esta una cuestión que sus propios habitantes 
intuyen, inscribiéndola sobre sus cuerpos como si fuesen las ruinas ambulantes de una profecía auto-cumplida: "Así se mueven los vecinos del barrio, lentos, como fantasmas a plena luz del día, caminando allí donde la tierra se ha comido los antejardines y las escaleras de entrada a los edificios" (104).

Para Rodrigo el desierto al mismo tiempo que emerge como el titán que devora los restos que la dinámica predatoria del capitalismo deja a su paso, funciona como un punto de fuga, una deriva que redefine su relación completa con la realidad. En el marco de los recuerdos que este enuncia, la ventana de su habitación de niño cuya vista da a los cerros cordilleranos del norte, opera como un punto de fuga de la mirada frente a la violencia vivida al interior de su familia a propósito del alcoholismo de su padre:

Recuerdo que terminaba una página y me asomaba a la ventana a ver los cerros: miraba sus colores, sus formas empinadas, las quebradas que había entre ellos, las zonas donde la tierra cambiaba de color; y años después, cuando podía decir con propiedad algunas cosas sobre la erosión de materiales de origen sedimentario, seguía mirando aquellos cerros como lo que eran: un lugar donde a veces me habría gustado esconderme cuando mi papá llegaba con trago y comenzaban los gritos. (62)

Ese primer acercamiento de Rodrigo con el desierto que determinará luego su relación con la geología implica una vuelta de espaldas al océano y al puerto que permanentemente observa su padre desde el balcón del edificio como una política impugnadora de la mirada. Su narración se da en el marco de distintas enunciaciones sobre el desierto que surgen de distintas entradas: de lo que dice éste durante el recorrido que realiza junto al fantasma de su padre, de lo que recuerda durante ese recorrido, y de la serie de reflexiones que van intercaladas a lo largo del texto y que funcionan como apuntes de campo. El conjunto de estas enunciaciones dan cuenta de una construcción paisajística del desierto cuya dimensión estética surge de la experiencia cognoscente del sujeto con el tiempo y el espacio. El desierto, de este modo, en tanto continente de las ciudades del norte, funcionaría como expresión de la materia misma del espacio/tiempo equiparable en su dimensión astronómica a la tierra, y sus habitantes como un punto perecedero dentro del inconmensurable tejido de la realidad. Su actividad de geólogo, en ese sentido, le permitirá enunciar el paisaje a partir de elementos como el sol y los cerros en su deambular por el desierto, pero también a partir de las formaciones geológicas como cuerpos que inscriben en su propio devenir eventos sucedidos 
Artículo. Cristofer Cepeda García. "La vuelta del padre y otras apariciones: Fantasmagorías de un paisaje en Geología de un planeta desierto de Patricio Jara"

en tiempos inmemoriales sujetos a escalas temporales más grandes en relación al conjunto de la historia humana, y que harían del mismo paisaje la expresión de lo inconmensurable: "Al amanecer o al final del día de pronto se tiene la certeza de que nada se ha movido de su sitio en millones de años. Es la quietud geológica y la indiferencia de la bóveda celeste que cambia de color." (98)

La luz ha sido objeto de reflexión para una buena parte del corpus discursivo de occidente. No solo para Platón y Aristóteles, sino también para el libro del génesis en tanto la tercera cosa creada por Dios después del cielo y la tierra, razón por la cual sus alcances llegan entre otras, hasta la escuela escolástica del medioevo desde donde el filósofo escolástico y franciscano Roberto Grosseteste afirmara "la primera forma corporal, a la que algunos llaman corporeidad, es la luz" (53). Dentro de la experiencia paisajística enunciada por el narrador, la luz forma parte de aquellos elementos que al dibujar los contornos de la materia, la dotan de corporeidad. Con respecto al problema de la temporalidad, la luz antecede y precede las cosas que pueblan la faz de la tierra. Por lo tanto, desde una dimensión metafísica, la luz se vuelve trascendente. Esto último concilia en un mismo plano la corporeidad de la imagen del padre como efecto de la luz en la habitación del narrador, su condición de fantasma, y la dimensión lumínica a la que pareciera pertenecer. De allí que pueda afirmarse, mediante la transformación del padre hacia el final del relato en el "chasquido imperceptible de un relámpago amarillo" (Jara, 127) que el padre que emerge desde la oscuridad del inconsciente de Rodrigo y que sirve de base para la enunciación de la fantasmagoría del paisaje, sea finalmente luz.

\section{Conclusiones}

Geología de un planeta desierto de Patricio Jara es una novela que sobre la base de la visita del padre muerto, articula una narración que permite la emergencia del cuerpo ausente y de la serie de sucesos inscritos en la memoria del narrador como una fantasmagoría al tiempo que se recorre la ciudad que habita.

La invitación del fantasma del padre de salir de casa a dar una vuelta, hace del paseo un eje vertebrador. Son los distintos lugares del circuito urbano del padre recorridos diariamente en vida los materiales que permiten la enunciación de un paisaje otro, distinto de 
la ciudad ejemplar del progreso minero, donde emergen los cuerpos dolientes desechados por el capitalismo neoliberal bajo la forma de estelas espectrales que el narrador en tanto observador sitúa en el espacio que visita.

La novela constituye una profunda reflexión sobre la muerte, la memoria, el olvido y el paso del tiempo, en cuyo caso la luz constituiría para el narrador un punto de fuga, el elemento que antecede y precede la emergencia misma de los cuerpos, y cuya enunciación permite la ontologización de la luz como base de una experiencia estética del desierto en tanto paisaje, estética que bajo el tópico de "la muerte igualadora" le permitirá al narrador la conciliación del conflicto psíquico a propósito de la muerte del padre.

Como perspectiva de futuras investigaciones queda abierto analizar los efectos de la desterritorialización inducida por la globalización en la enunciación de una determinada forma de paisaje. Aquello daría cuenta de un uso predatorio del espacio que impacta dramáticamente en su morfología. Comportaría interés a su vez la construcción de un acervo teórico sobre la metafísica de la luz para el análisis de la representación paisajista en la narrativa de Jara, así como en otras novelas situadas en el norte de Chile.

\section{Referencias}

Arancibia Venegas, Felipe. “Geología de un planeta sombrío”. Alpha núm. 47, 2018, pp. 239252.

Benjamin, Walter. Tesis sobre el concepto de historia y otros ensayos sobre historia y política. Alianza editorial, 2021.

Díaz Cuyás, José. "La imagen fantasma: introducción”. Revista de pensamiento contemporáneo, núm. 4, 2008, pp. 52-53.

Didi-Huberman, Georges. Fasmas. Ensayos sobre la aparición 1. Sangrila textos aparte, 2015.

---. Imágenes pese a todo. Memoria visual del Holocausto. Paidós, 2004.

Grosseteste, Robert. Acerca de la luz o del comienzo de las formas. Editorial Universitaria, 2017.

Guerra, Lucía. Ciudad, género e imaginarios urbanos. Editorial Cuarto Propio, 2013.

Harvey, David. Breve historia del neoliberalismo. Ediciones Akal, 2007.

Jara, Patricio. Geología de un planeta desierto. Alfaguara, 2013.

Kofman, Sarah. Cámara oscura de la ideología. Taller de ediciones Josefina Betancor, 1975.

Maderuelo, Javier. "Paisaje: un término artístico". Paisaje y arte. Abada Editores, S.L., 2007, pp. 11-36.

Mouat, Francisco. El empampado Riquelme. Lolita editores, 2012.

Negri, Antonio. De la fábrica a la metrópolis. Editorial Cactus, 2020. 
Artículo. Cristofer Cepeda García. "La vuelta del padre y otras apariciones: Fantasmagorías de un paisaje en Geología de un planeta desierto de Patricio Jara"

Nogué, Joan. "La valorización cultural del paisaje en la cultura contemporánea". El paisaje en la cultura contemporánea, editado por Federico López, Javier Maderuelo y Joan Nogué. Madrid: Editorial Biblioteca Nueva, 2008, pp. 9-24.

Pizarro, Sergio. "Orfandades de la globalización en la novela Geología de un planeta desierto de Patricio Jara", 2019, www.letras.mysite.com. Consultado el 15 de junio de 2021.

Pradilla, Emilio. "La ciudad capitalista en el patrón neoliberal de acumulación en América Latina". Cadernos Metrópole, vol. 16, núm. 31, 2014, pp. 37-60.

Ruiz, Carlos. La política en el neoliberalismo, experiencias latinoamericanas. LOM ediciones, 2019.

Solnit, Rebecca. Wanderlust: una historia del caminar. Capitán Swing, 2015. 